\title{
Shrimp disease disinfection and phytoplankton control of intensive shrimp pond water by electro-oxidation process
}

\author{
Niwooti WHANGCHAI, ${ }^{1 *}$ Catalino AlFAFARA, ${ }^{2}$ NaKao NOMURA, $^{2}$ Henry YOUNG ${ }^{3}$ AND \\ MASATOSHI MATSUMURA ${ }^{1}$ \\ ${ }^{1}$ Institute of Applied Biochemistry, University of Tsukuba, Tsukuba 305-8574, Japan. ${ }^{2}$ Science and Technology \\ Promotion Foundation of Ibaraki, Japan. ${ }^{3}$ Aqua-Ecotechnology Research, Inc. (AERI), Quezon City, Philippines \\ (e-mail:aquacel@sakura.cc.tsukuba.ac.jp)
}

\section{KEY WORDS: shrimp disease, disinfection, phytoplankton control, electro-oxidation}

\section{INTRODUCTION}

Recently, shrimp culture in many countries have been confronted with outbreaks of diseases and environmental problems. Phytoplankton die-off and consequent proliferation of pathogenic bacteria remain to be one of the serious problems in intensive shrimp cultivation. ${ }^{1)}$ During cultivation, mass mortality of shrimp was observed to coincide with the blooms of some species of Oscillatoria. ${ }^{2)}$ Severe mortality of juvenile shrimp occurred due to luminous vibrios. Although some phytoplankton are beneficial in shrimp ponds, some species can produce compounds that are extremely toxic to aquatic animals. Sub-lethal levels of toxins weaken the prawns causing predisposition to secondary infection by pathogenic bacteria. ${ }^{2)}$ Thus the control of the number of phytoplankton is necessary in intensive shrimp farm. Electrolytic oxidation (EO) treatment has been found to be effective for controlling phytoplankton overbloom, as well as the proliferation of pathogens in shrimp pond water. In this study, the influence of anode type, energy input and water quality on Vibrio inactivation and phytoplankton reduction was investigated.

\section{MATERIALS AND METHODS}

Shrimp pond water, either as natural shrimp pond water or artificial seawater containing Skeletoma (from NIES, Japan) as the model phytoplankton, and Vibrio harveyi (from Dept. of Fisheries, Thailand) as the model shrimp pathogen, were used for electrolysis experiments. Electrolytic oxidation experiments were conducted in a batch reactor with working volumes of $3 \mathrm{~L}$ and $8 \mathrm{~L}$ using a DC power source (GSV 3000, Diamond Company, Japan) controllable between 0 to 15 volts. Mixing was done either with a magnetic stirrer or a submerged jet aerator. Different electrode materials such as titanium base metal sintered with platinum, iridium or ruthenium, or coated with $\mathrm{TiO}_{2}$, were tested; stainless steel was used as cathode. The total Vibrio counts (TVCs), phytoplankton level as chlorophyll $a$ concentration, total residual oxidants (TROs) ${ }^{3)}$, ammonia and chemical oxygen demand (COD) ${ }^{4)}$ were monitored.

\section{RESULTS}

Fig. 1 shows the time course of phytoplankton concentration (in terms of chlorophyll a) during EO using different types of anodes. Complete removal of chlorophyll $a$ was achieved within 5 min for all anodes tested. The anode type had no significant effect on phytoplankton removal. In succeeding experiments, the Ti coated with $\mathrm{TiO}_{2}$ anode was used.

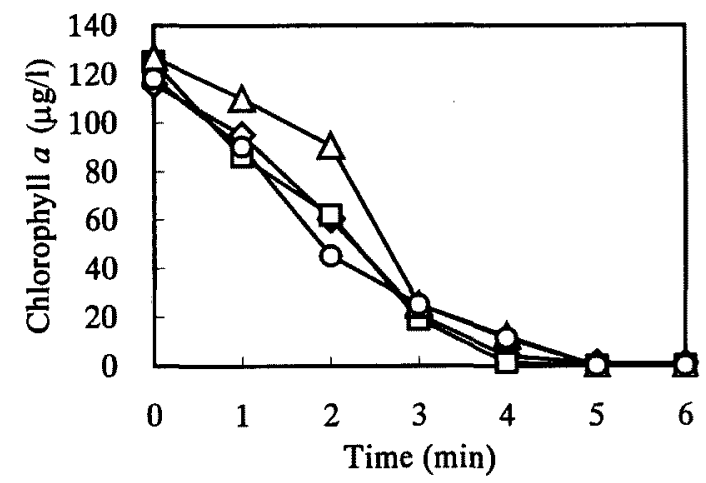

Fig. 1. Changes in chlorophyll $a$ during EO with different anode types; $(\Delta) \mathrm{Ti} / \mathrm{Ir},(\square) \mathrm{Ti} / \mathrm{Pt},(\diamond) \mathrm{Ti} / \mathrm{TiO}_{2}$, (o) $\mathrm{Ti} / \mathrm{Ru}$; Operate with $0.5 \mathrm{~A}$.

Efficiencies for the removal of phytoplankton, Vibrio and COD by EO was affected by the amount of energy input as shown in Fig. 2. Higher volumetric energy input increased the removal efficiency. The increase in removal efficiency was highest for Vibrio, and followed by chlorophyll $a$. The increase in removal efficiency for COD by EO was relatively slow. The removal rates per energy input are shown in Table 1. The amount of energy in an actual process will depend on which target is chosen for removal (phytoplankton, Vibrio or COD) and how much they are present in the water. Fig. 3 shows the relationship between TROs and electric quantity during electrolysis with $2.8 \mathrm{~cm}^{2}$ area 
of $\mathrm{Ti} / \mathrm{TiO}_{2}$ anode. The graph shows that $13.6 \mathrm{mg}$ of oxidants (as TROs) are formed for every coulomb of electricity.

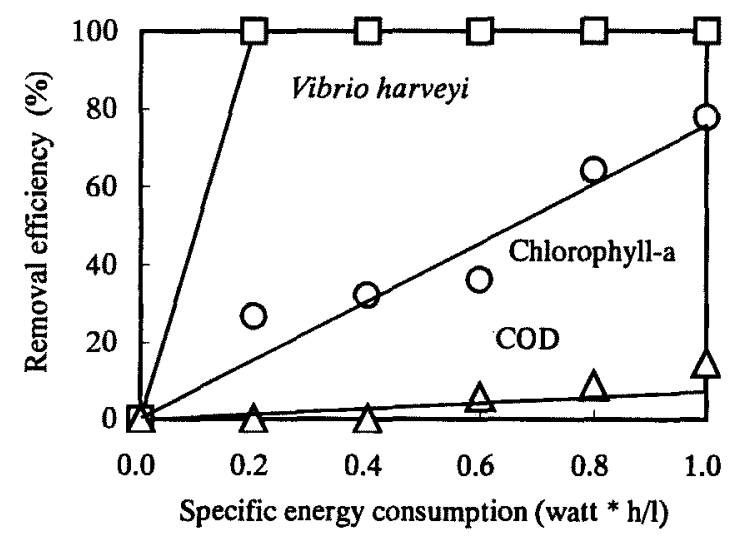

Fig. 2. Changes in phytoplankton, $V$. harveyi, and COD in artificial seawater after electro-oxidation with different specific energy consumption; $\mathrm{Ti} / \mathrm{TiO}_{2}$ and stainless plate were anode and cathode, respectively; () V. harveyi, (०) Chlorophyll $a,(\Delta)$ COD. The operating condition was 60 watts power supply and 0 to 3 minutes of electro-oxidation time.

Table 1. Removal rate of Vibrio, phytoplankton and COD after EO

\begin{tabular}{ll}
\hline Parameter & Removal rate \\
\hline Vibrio harveyi & $>5 \times 10^{4} \mathrm{CFU} /$ watt hour \\
Chlorophyll $a$ & $276 \mu \mathrm{g} /$ watt hour \\
COD & $10.3 \mathrm{mg} /$ watt hour \\
\hline
\end{tabular}

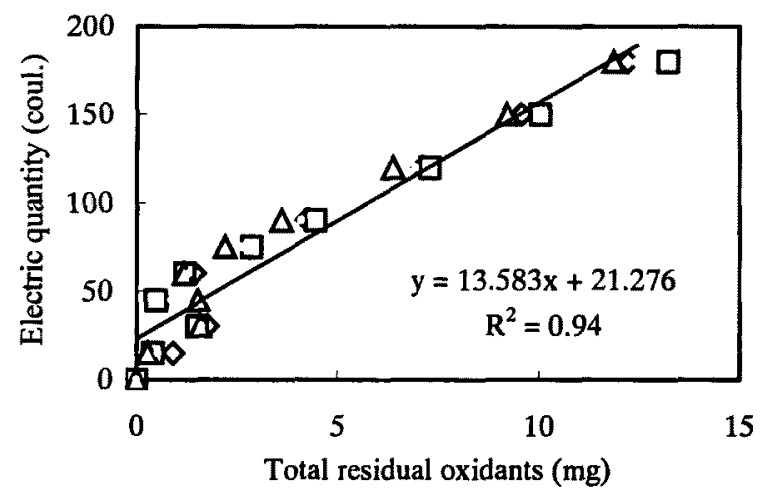

Fig. 3. Relationship between TRO and electric quantity during electrolysis with $0.05(0), 0.10(\square)$ and $0.20(\Delta)$ ampere; $2.8 \mathrm{~cm}^{2}$ area of $\mathrm{Ti} / \mathrm{TiO}_{2}$ anode

\section{DISCUSSION}

Electro-oxidation process involving the electrolysis of seawater is categorized as an indirect type of environmental electrolysis. The oxidation of COD, and the removal of phytoplankton and Vibrio do not occur mainly on the electrode, but by the oxidants/ disinfectants produced at the anode. These oxidants/ disinfectants are mainly forms of hypochlorous and hypobromous acids which are formed by reaction of water with chlorine and bromine formed from the oxidation of chloride and bromide at the anode. Therefore, the removal of Vibrio, phytoplankton and COD in shrimp pond water is a direct action of the oxidants formed at the anode. For practical application of this process, it will be necessary to know how much of oxidants are formed, and how much of oxidants are required for the removal of unit amounts of phytoplankton, Vibrio and COD. Once the "oxidant doses" for the removal of these elements are known, and if the relationship between oxidant formation and electrolysis conditions (i.e. electric current) are known, then the operating condition for an actual process can be calculated from the relationship between TROs and operating current at the different electrolysis times (Fig. 3). The oxidant doses for removal of unit amount of phytoplankton, Vibrio and COD were calculated to be about $1.6 \times 10^{-2} \mathrm{mg} \mathrm{TRO} / \mu \mathrm{g}$ chl-a, $8.8 \times 10^{-5} \mathrm{mg}$ TRO/CFU Vibrio and $0.4 \mathrm{mg}$ TRO/ppm COD. The laboratory conditions obtained will be evaluated and applied for testing in actual shrimp ponds.

\section{REFERENCES}

1. Matsumura M, Whangchai N, Migo VP, Young HK, Alfafara CG and Nomura N. Effects of algae die-off on shrimp cultivation in ponds using ozonation. Proceedings of the JSPSNRCT International Symposium on Sustainable Shrimp Aquaculture and Health Management Diseases and Environment. Tokyo University of Fisheries, Japan 2001; 7387.

2. Smith TP. Toxic effects of blooms of marine species of Oscillatoriales on farmed prawns (Penaeus monodon, Penaeus japonicus) and brine shrimp (Artemia salina). Toxicon 1996; 34: 857-869.

3. Shechter H. Spectrophotometric method for determinination of ozone in aqueous solutions. Water Res. 1973; 7: 729-739.

4. Ruttanagosrigit $W$ and Boyd CE. Measurement of chemical oxygen demand in water of high chloride concentration. $J$. World Aquacult. Soc. 1989. 20:170-172. 